\title{
Procyclicality in Basel II: \\ Can We Treat the Disease Without Killing the Patient?
}

\author{
Michael B. Gordy and Bradley Howells* \\ Board of Governors of the Federal Reserve System
}

First draft: April 25, 2004

This draft: May 12, 2004

JEL Codes: G31, G38

*The views expressed herein are our own and do not necessarily reflect those of the Board of Governors or its staff. We thank Allen Berger, Mark Carey, Erik Heitfield and Tom Wilde for helpful comments. Email: $\langle$ michael.gordy@frb.gov $\rangle$ or $\langle$ bradley.t.howells@frb.gov $\rangle$. 
Academics, practitioners and policy makers have commented on the potential procyclicality of the New Basel Capital Accord. So long as bank rating systems are responsive to changes in borrower default risk, capital requirements under the proposed Internal Ratings Based (IRB) approach will tend to increase as an economy falls into recession and fall as an economy enters an expansion. To the extent that banks curtail (expand) lending in response, recessions (expansions) will be amplified. Thus, many have argued that the New Accord will make it more difficult for policy makers to maintain macroeconomic stability.

The New Accord is composed of three complementary "pillars." Pillar 1 is a regulatory standard for minimum capital requirements. In the Third Consultative Paper (Basel Committee on Bank Supervision (2003), henceforth cited as "CP3"), as in earlier drafts of the proposal, the great bulk of the documentation is devoted to the rules for determining minimum capital requirements, and it is this aspect of the New Accord that has drawn the most commentary from practitioners and academics. The primary objective under Pillar 1 is better alignment of regulatory capital requirements with "economic capital" demanded by investors and counterparties. Under the current Accord, all commercial lending is subject to the same $8 \%$ capital requirement regardless of the creditworthiness of the borrower and collateral strength of the loan. ${ }^{1}$ The failure to distinguish among commercial loans of very different degrees of credit risk created the incentive to move low-risk instruments off balance sheet and retain only relatively high-risk instruments. As documented by Jones (2000), the financial innovations that arose in response to this incentive have provided banks with the means to "arbitrage" differences between regulatory and economic capital. These arbitrage activities have been beneficial in minimizing allocative inefficiency in lending markets. Had banks not been able to circumvent the current Accord at relatively low cost, they would have been put to competitive disadvantage against non-bank lenders for high quality borrowers. From a regulatory perspective, however, regulatory capital arbitrage has undermined the effectiveness of the 1988 Accord. At least for large banks, capital ratios under the current Accord are no longer reliable measures of capital adequacy.

Pillar 2 is the supervisory review process. The New Accord sets forth broad principles and some specific guidelines for review of capital adequacy that are intended to push both banks and supervisors beyond mechanical application and satisfaction of Pillar 1 standards. Banks are expected to establish and document internal processes for assessing capital adequacy relative to portfolio risk. The stated intent of the Basel Committee (CP3, 9715a) is that large, internationally active banks will choose for their own competitive reasons a level of creditworthiness that exceeds that embodied in Pillar 1 standards, which corresponds approximately to an A- or BBB+ rating. Furthermore, banks' internal processes are expected to include consideration of interest rate risk, liquidity risk, concentration risk, and other risks not explicitly addressed under Pillar 1. Therefore, "[s]upervisors should expect banks to operate above the minimum regulatory capital ratios and should have the ability to require banks to hold capital in excess of the minimum" (CP3, \714). Regulatory capital requirements should properly be viewed as a composite of formulaic Pillar 1 rules and judgmental Pillar 2 buffers, so the volatility of regulatory capital over the business cycle will depend in practice on whether supervisors guide Pillar 2 buffers in a manner that offsets or augments changes in Pillar

\footnotetext{
${ }^{1}$ The so-called $8 \%$ rule takes a rather broad definition of "capital.” In effect, roughly half this $8 \%$ must be in equity capital, as measured on a book-value basis. A very limited degree of risk-sensitivity is achieved through discounts to the standard $8 \%$ that are applied to certain special classes of lending, e.g., to OECD member governments, to other banks in OECD countries, and for residential mortgages.
} 
1 requirements.

Pillar 3 is market discipline. In order to improve the transparency of banks to counterparties and investors, banks will be required to disclose detailed information on their risk profile and capital adequacy. Specific reporting requirements include IRB capital for each of the major portfolio components (e.g., corporate, retail mortgages, securitization exposures) as well as for the bank as a whole. We take the view that the ultimate success of Pillar 1 standards rests on how well the resulting disclosures serve Pillar 3 goals. A well-functioning bank will hold capital well in excess of the minimum requirement, so the regulatory capital ratio will not be binding under Pillar 1. If, for such institutions, the disclosed capital ratio provides a reliable measure of economic capital adequacy, then it will allow market participants to better assess relative creditworthiness both cross-sectionally (i.e., across investment-grade banks at a moment in time) and across time. The earlier market participants are able to identify and punish a faltering institution, the less the need for supervisory intervention. ${ }^{2}$

Under present standards for public disclosure, banking is often regarded as among the most difficult sectors for market participants to analyze. Traditional rating methods based on accounting measures are hampered by the opacity of bank assets (Morgan 2002). Structural approaches based on the Merton (1974) model, such as KMV Portfolio Manager, require calibration of the "default threshold" implied by a firm's liabilities. Compared to large non-financial firms, large bank liability structures are often quite complex, which makes calibration judgment-dependent and error prone. Some large banks disclose results of internal value-at-risk (VaR) exercises, but these disclosures appear to be regarded with great suspicion by practitioners. As details are generally not made public, the VaR models may be perceived as "black boxes" by outsiders. The processes by which input data (such as internal ratings) are obtained are unaudited and often just as murky as the models. Perhaps more importantly, proprietary idiosyncracies in internal capital systems render cross-bank comparisons impossible. For these reasons, anecdotal evidence suggests that many analysts continued to rely on the reported capital ratios of the current Accord long after regulatory capital arbitrage rendered these numbers almost meaningless.

At least in principle, the IRB approach of the New Accord offers a far more sophisticated and informative measure of capital adequacy. IRB capital formulae are derived from asymptotic approximations to the risk-factor models that are now in widespread use in the banking industry. For large, well-diversified banks, regulatory capital under the IRB approach should roughly approximate VaR for a one-year solvency probability of $99.9 \%$. For whatever its limitations, the IRB capital ratio represents the first standardized modern metric of portfolio risk. Even if it comes at some sacrifice in sophistication and risk-sensitivity, an imposed common standard provides the benefit of easier and more direct comparison of creditworthiness between banks and across time. This enhanced comparability is indeed an explicit Basel Committee objective under Pillar 3 (CP3, ๆ759).

The burgeoning literature on the procyclicality of the New Accord is written mainly from the perspective of Pillar 1. That is, the focus is on estimation of the likely range of variation in regulatory capital requirements from peak to trough in a business cycle, and on how modifications to the proposed New Accord might

\footnotetext{
${ }^{2}$ This principle motivates many proposed reforms to bank regulation, e.g., proposals for requiring banks to issue subordinated notes and debentures (Study Group on Subordinated Notes and Debentures 1999).
} 
increase or decrease this variability. Discretionary powers granted to supervisors under Pillar 2, such as the ability to demand a buffer of additional capital during a business cycle expansion, are sometimes considered as possible ways to address procyclicality. In this paper, the perspective is predominantly that of Pillar 3 . We evaluate potential solutions to the procyclicality problem not only in terms of efficacy in dampening cyclicality in capital requirements, but also in terms of how well the information value of the IRB capital ratio is preserved.

Broadly speaking, there are three methods by which the procyclical impact of the IRB approach could be dampened. First, banks could adopt through-the-cycle rating methodologies which "filter out" the impact of the business cycle on borrower ratings. Assuming that the probability of default (PD) associated with each rating grade is calculated as a long-term historical average, through-the-cycle systems dampen the sensitivity of borrower PDs to macroeconomic conditions. By smoothing these critical inputs to the Basel capital function, smoothing of the output (i.e., the regulatory capital requirement) is obtained. Second, procyclicality can be reduced simply by flattening the IRB capital function in order to reduce the sensitivity of capital charges to changes in PD. Third, supervisors can apply a smoothing rule directly to the output of the IRB capital function. Let $C_{i t}$ denote the unsmoothed output from the IRB capital formula for bank $i$ at time $t$, expressed as a percentage of portfolio book value, and let $\hat{C}_{i t}$ denote the corresponding regulatory minimum applied to the bank. At present, the proposed New Accord sets $\hat{C}_{i t}=C_{i t}$. One simple smoothing rule would specify $\hat{C}_{i t}$ as an autoregressive process that adjusts towards $C_{i t}$, i.e.,

$$
\hat{C}_{i t}=\hat{C}_{i, t-1}+\alpha\left(C_{i t}-\hat{C}_{i, t-1}\right)
$$

The current Accord can be represented in stylized fashion as setting $\alpha=0$, whereas the proposed New Accord sets $\alpha=1$. An intermediate value of $\alpha$ would offer a compromise between the current Accord and New Accord in sensitivity to the business cycle. A more sophisticated smoothing rule would apply a time-varying multiplier to the IRB formula, that is, $\hat{C}_{i t}=\alpha_{t} C_{i t}$. The multiplier $\alpha_{t}$ would be reduced by regulators during a recession to offset the effect of higher borrower PDs on required capital. During an expansion, $\alpha_{t}$ would be increased, and similarly offset the effect of fallings PDs. We call this alternative "counter-cyclical indexing."3

From a Pillar 1 perspective, any of these approaches could in principle provide a practical solution to the procyclicality problem. From a Pillar 3 perspective, however, the three approaches have very different implications. We show that adoption of through-the-cycle rating systems would destroy the comparability across time of the IRB capital requirement. Market participants would be unable to infer changes in portfolio risk from changes in a bank's capital ratio. As through-the-cycle rating is also poorly suited for internal pricing and risk-management purposes, we strongly recommend against this approach. We find that flattening the IRB capital function is much less destructive to the information value of the capital ratio across banks and across time, but one can achieve only very modest degree of smoothing without causing significant distor-

\footnotetext{
${ }^{3}$ Ervin and Wilde (2001) refer to counter-cyclical indexing as "explicit regulatory guidance," and appear to have been the first to suggest this method for dampening procyclicality. Similar proposals have also been put forward by Kashyap and Stein (2004), Purhonen (2002), Rösch (2002), and Cosandey and Wolf (2002). So far as we are aware, we are the first to explore the desirability of an autoregressive rule.
} 
tion to relative capital charges across borrowers. Finally, we demonstrate that smoothing the IRB output can dampen procyclicality significantly. The autoregressive rule has somewhat different implications from counter-cyclical indexing for cross-sectional variation in capital adequacy and for robustness to changes in bank business strategy. However, so long as the dampening rule is publicly announced, the unsmoothed capital requirement $\left(C_{i t}\right)$ can be inferred from the regulatory minimum $\left(\hat{C}_{i t}\right)$. Thus, the prospect of transparent and informative Pillar 3 disclosure is undiminished under either alternative.

The empirical evidence on the degree of procyclicality in the IRB capital formula is examined in Section 1. Existing studies have focused on the mechanics of the regulatory capital minimum, rather than on the constraints placed on banks in the marketplace, and so may overstate the magnitude and economic significance of procyclicality in the New Accord relative to the current Accord. In Section 2, we describe a flexible simulation engine for exploring the cyclical behavior of regulatory and economic capital under different rating philosophies, various assumptions on how bank lending behavior responds to the business cycle, and alternative proposed modifications to the New Accord. Results are presented in Section 3. A concluding Discussion addresses practical issues in implementation.

\section{Evidence on procyclicality in the proposed New Accord}

Existing studies of procyclicality in the proposed New Accord have focused on Pillar 1 IRB treatment of whole commercial loans. ${ }^{4}$ Regulatory capital charges are set at the individual loan level and are given by a formula with five inputs: the borrower's one-year PD, the instrument's expected loss given default (LGD) and remaining maturity (M), the asset-value correlation $(\rho)$ which parameterizes dependence across borrowers, and a target one-year solvency probability $(q)$ for the bank. Parameters $q$ and $\rho$ are controlled by the regulator. Under CP3, $q$ is fixed to $99.9 \%$ and $\rho$ is specified as a decreasing function of PD. The IRB approach comes in Foundation and Advanced flavors. Under the Foundation approach, the bank supplies only the borrower's PD. LGD is set to $45 \%$ and maturity to $M=2.5$ years. Under the Advanced approach, the bank supplies PD, LGD and M for each loan. Expressed as a share of investment book value, capital is given $b^{5}$

$$
K_{\mathrm{irb}}=\mathrm{LGD} \cdot V(\mathrm{PD}, \rho, q) \cdot h(\mathrm{PD}, M)
$$

where $V(\mathrm{PD}, \rho, q)$ is the so-called Vasicek distribution

$$
V(\mathrm{PD}, \rho, q)=\Phi\left(\frac{\Phi^{-1}(\mathrm{PD})+\sqrt{\rho} \cdot \Phi^{-1}(q)}{\sqrt{1-\rho}}\right)
$$

\footnotetext{
${ }^{4}$ Large banks typically have significant portfolios of retail loans, sovereign loans, commercial real estate project finance, and securitization exposures. Treatment of these other lending classes is based on the same principles and models that underpin treatment of commercial lending.

${ }^{5}$ Technically, this rule expresses capital as a share of the bank-supplied estimated exposure at default (EAD). For whole loans, EAD is book value. For lines of credit, EAD reflects the bank estimate of likely drawdown prior to a default.
} 
and the maturity adjustment $h(\mathrm{PD}, M)$ is calculated as

$$
\begin{aligned}
h(\mathrm{PD}, M) & =\frac{1+(M-2.5) \cdot b(\mathrm{PD})}{1-1.5 \cdot b(P D)} \\
b(\mathrm{PD}) & =(0.08451-0.05898 \cdot \log (\mathrm{PD}))^{2} .
\end{aligned}
$$

This capital rule is derived from the large-portfolio asymptotic behavior of a Merton model with a single common risk-factor. As shown by Gordy (2003), an instrument's marginal contribution to portfolio VaR converges in the asymptotic limit to its expected loss conditional on the common factor suffering a $q^{\text {th }}$ percentile "stress event." In the IRB implementation, this conditional expected loss is approximated as a separable equation of three terms: LGD; the one-year actuarial conditional expected loss, $V(\mathrm{PD}, \rho, q)$; and a maturity adjustment $h(\mathrm{PD}, M)$ that approximates the ratio of mark-to-market capital charges to actuarialloss capital charges. ${ }^{6}$

Since the release of the Second Consultative Paper (Basel Committee on Bank Supervision 2001a), nearly a dozen studies have assessed empirically the magnitude of procyclicality in the proposed IRB capital formula. Both within and between studies, one sees a wide range of estimated response to a cyclical downturn. Required capital can double in some simulations, and in others can actually decline. Kashyap and Stein (2004) point to differences across studies in sample and methodology that account for some of the differences in results. These include

- Construction of the sample portfolio: The concavity of the IRB capital function with respect to PD implies that capital on higher quality portfolios is more sensitive to volatility in borrower PDs than is capital on lower quality portfolios.

- Geography and time period: Studies have drawn on the experience of different countries (e.g., US, Germany, Sweden, Spain, Mexico) and different recessions (e.g., 1990-91 vs. 2000-02).

- Default and migration probabilities: The magnitude of procyclicality in regulatory capital depends on the transition matrix associated with the rating system. Relative to point-in-time systems, throughthe-cycle systems display greater stability in ratings, and therefore lower volatility in the IRB capital assigned to non-defaulting borrowers. Consequently, Kashyap and Stein (2004) and Catarineu-Rabell, Jackson and Tsomocos (2003) find greater procyclicality in simulations calibrated to the transition behavior of KMV EDFs (widely regarded as the benchmark point-in-time rating system) than in simulations calibrated to agency rating histories.

- Revisions to the IRB formula: The CP3 IRB formula differs from the CP2 formula in target solvency standard $(q)$, assumed asset-correlation $(\rho)$, Foundation maturity assumption (2.5 years in CP3 vs. 3 years in $\mathrm{CP} 2)$, and calibration of maturity adjustment $(h(\mathrm{PD}, M))$. These changes may account for a portion of the differences across studies written under different regulatory proposals.

\footnotetext{
${ }^{6}$ The maturity adjustment is calibrated to the slope of a linear approximation to the term structure of mark-to-market capital charges in KMV Portfolio Manager (version 1.4). The slope is in turn approximated as a function $b(\mathrm{PD})$ of the one-year PD.
} 
Kashyap and Stein (2004) also identify methodological issues in survivorship bias and treatment of missing observations that appear to have been mishandled in some earlier studies. Perhaps more important are two issues that can be cast as methodological, but have strong substantive implications. First, should measurement of changes over time in required capital be inclusive or exclusive of charge-offs due to defaulted loans? Second, should the simulated portfolio be passively or actively managed? A passively managed portfolio is fixed at the beginning of the simulation, and so shrinks as defaults accumulate. In an actively managed portfolio, defaulting or maturing loans are replaced with new loans. We can assume a simple timeinvariant rule for new lending, or we can attempt to emulate the behavior of bank managers in loosening or tightening lending standards over the credit cycle. ${ }^{7}$

As Kashyap and Stein (2004) observe, if we retain defaulted loans in the sample, then we measure the cumulative demands on bank capital over the simulated period. The accumulated charge-offs would have been incurred under the rules of the current Accord as well. From a policy perspective, we are interested only in the additional procyclicality associated with a change in capital regime. Furthermore, in our view it is somewhat misleading to include accumulated charge-offs without also imputing accumulated interest income net of dividend payments. Dividends can be raised and lowered with the anticipated capital needs of the bank, so would need to be modeled endogeneously. Therefore, we concur with Kashyap and Stein in preferring to measure capital changes exclusive of defaulted obligors. In most of their simulations, Kashyap and Stein (2004) find that roughly $40 \%$ to $60 \%$ of total change in capital (inclusive of defaulted loans) is attributable to accumulated charge-offs. When Catarineu-Rabell et al. (2003) and Rösch (2002) similarly decompose total changes in required capital, they in some cases find that capital on the non-defaulting portfolio can decrease in a credit cycle downturn. By sweeping away the weakest borrowers, a stress event can paradoxically improve the average credit quality in a portfolio.

On the second issue, Kashyap and Stein favor a passive simulated portfolio because

active management muddles together the direct effect of a tightened capital constraint with the bank's endogenous response. For example, suppose we look at the evolution of a bank's actively managed portfolio during a recession and find that average credit quality ... is roughly unchanged. Should we conclude from this that there is no cyclicality problem deserving of policymaker attention? Probably not-it may just be that the bank has reacted to a tightening capital constraint by cutting off credit to its riskier borrowers, which is precisely the policy problem that concerns us (Kashyap and Stein 2004, p. 23).

Here we disagree. If the goal is to estimate the additional procyclicality associated with the proposed change in capital regime, then we need to simulate active portfolio management as it occurs under the current regulatory regime. Put another way, we agree with Kashyap and Stein that portfolio management should not be made endogenous to the regulatory rule, but disagree on the appropriate alternative benchmark. Since the mid 1990s, large banks have been more or less unconstrained by regulatory capital requirements, so changes in lending standards over recent years ought to have been driven mainly by economic capital considerations. Such considerations are independent of regulatory regime, and thus would persist (though not necessarily as

\footnotetext{
${ }^{7}$ In the last few years, banks have begun to use credit default swaps and secondary loan markets to manage the stock of existing loans from earlier cohorts. Our study, like earlier studies, does not attempt to model this aspect of active management.
} 
the binding constraint) into a New Accord. ${ }^{8}$

Empirical evidence is limited on this point, but suggests that banks currently do tighten lending standards during a recession and loosen lending standards in an expansion. Bassett and Zakrajšek (2003) show that the average quality of new loans decreased at the start of the recent recession, while the Federal Reserve Board's Senior Loan Officers Survey showed a contemporaneous tightening of lending standards. These results are not necessarily contradictory. Many or most nominally "new" loans are actually drawdowns under existing commitments. Tighter lending standards presumably increase the quality of newly established lending facilities. Thus, the change in loan quality takes effect with a lag. ${ }^{9}$ Taking a more behavioral view of lending practices, Berger and Udell (2003) find evidence for a "memory hypothesis" under which standards soften as time passes since a bank's most recent period of large credit losses. The ability to differentiate accurately between high risk and low risk borrowers deteriorates over time as loan officers forget the lessons of the last credit cycle. When large losses are again experienced, standards are tightened drastically, and the cycle begins again.

Results in Kashyap and Stein (2003) are consistent with this story. In addition to studying procyclicality on their simulated passive portfolios, Kashyap and Stein calculate the time-series of IRB required capital for Deutsche Bank's actual German commercial loan portfolio. The capital increase (excluding charge-offs) in this actively managed portfolio was only about one-fourth of the increase in required capital for the passively managed, simulated KMV Germany portfolio. As the Deutsche Bank rating system is designed to be pointin-time like KMV, it is reasonable to attribute the difference to active management of lending standards. ${ }^{10}$ Thus, even under the current risk-insensitive Accord, internal management processes cause banks to respond to a downturn in a manner that would also serve to dampen the cyclicality of IRB capital requirements.

The distribution of credit ratings is only one dimension of lending standards for bank to manage. Banks can tighten standards by reducing maturity or increasing collateral. So far as we are aware, all existing studies of procyclicality in the New Accord follow the Foundation approach and so impose fixed values on LGD and $M$. This greatly simplifies the analysis, as there is then no need to collect data on (or otherwise specify) the distribution of these parameters in bank portfolios, but may overstate the procyclicality of capital under the Advanced IRB. Most large banks can be expected to opt for Advanced IRB treatment as quickly as data systems permit. In the US, the Foundation IRB will not even be offered as an option. Rather, the largest banks will be required to adopt the Advanced approach. ${ }^{11}$

\footnotetext{
${ }^{8}$ It should also be noted that endogenous response by banks to a New Accord might serve to reduce cyclicality in regulatory capital without exacerbating macroeconomic cycles. If the New Accord encourages more forward-looking behavior on the part of bank managers, then banks might exhibit less "irrational exuberance" during an expansion. The Basel Committee on Bank Supervision (2001b, $\uparrow 41)$ points out that "The 1988 Accord, which does not adequately reflect changes in risk, creates incentives for banks to make high-risk investments that may contribute to cyclicality over the business cycle.” Jordan, Peek and Rosengren (2003) argue that improved risk-sensitivity under the New Accord will encourage banks to recognize and correct capital inadequacies earlier in the cycle, and so may prevent the sudden precipitous declines in capital adequacy that trigger credit crunches.

${ }^{9}$ The predicted response of credit quality in new loans to a downturn is analogous to the "J-curve" response of the trade balance to a currency depreciation in the international trade literature.

${ }^{10}$ The characterization of Deutsche Bank's ratings as point-in-time is consistent with the bank's public statements on the issue. Historical transition frequencies for Deutsche Bank's rating system, found in Kalkbrenner and Overbeck (2002), are indeed more consistent with a transition matrix from KMV migration data than with the S\&P transition matrix.

${ }^{11}$ See speech by Federal Reserve Board Vice-Chairman Roger W. Ferguson, Jr., "Concerns and Considerations for the Practical Implementation of the New Basel Accord," December 2, 2003.
} 
At a purely mechanical level, the maturity adjustment in the Advanced IRB reduces the sensitivity of capital to downgrades. Consider a three year loan to an AA-rated borrower (say, PD of 4bp). If the borrower is downgraded to A (say, PD of 10bp) after one year, the capital charge under the Advanced approach increases by $36 \%$ (that is, $K_{\mathrm{irb}}(\mathrm{PD}=10 \mathrm{bp}, M=2, L G D) / K_{\mathrm{irb}}(\mathrm{PD}=4 \mathrm{bp}, M=3, L G D) \approx$ 1.36 ). The corresponding increase under the Foundation approach is $79 \%$ (that is, $K_{\operatorname{irb}}(\mathrm{PD}=10 \mathrm{bp}, M=$ $\left.2.5, L G D) / K_{\mathrm{irb}}(\mathrm{PD}=4 \mathrm{bp}, M=2.5, L G D) \approx 1.79\right)$. The corresponding increases for a three year BBrated (PD of 71bp) loan that downgrades to a two year B-rated (PD of 2\%) are 64\% under the Advanced approach and $84 \%$ under the Foundation approach. The larger relative effect of maturity at lower PD levels reflects the declining slope of the maturity adjustment $b(\mathrm{PD})$ with respect to PD. Procyclicality under the Foundation approach is more severe at lower PD levels, so taking account of the Advanced IRB option is most important for investment grade portfolios.

If bank managers do not vary the distribution of maturities in new loans over the business cycle, then cyclical variation in the overall distribution of maturities in the portfolio may not vary very much. So far as we are aware, variation in maturity terms over the business cycle has not been addressed in the literature. We analyze maturity terms in the Loan Pricing Corporation's Dealscan database of loans issued to US business borrowers from 1988 to 2002. This database is considered representative of US banks' commercial lending to medium-sized to large firms and contains almost 70000 loan agreements over our sample period; see Carey, Post and Sharpe (1998) for more detailed description of Dealscan data. In Figure 1, we plot the average maturity of annual cohorts of new loans. We see a decline in average maturity in the recession of 1990-91, a steady increase in average maturity through the expansion of the 1990s, and then a large drop of almost 0.9 years between 1998 and 2001. The IRB maturity input $M$ is bounded at one year from below and at five years from above, so we also plot the average truncated maturity as well and see a similar pattern. Of course, the cyclical decline in average maturity could reflect cyclical patterns in loan demand rather than in loan supply. Either way, the effect is to dampen the cyclicality of Advanced IRB capital requirements.

Less obvious is whether the LGD parameter in the Advanced approach will dampen or enhance cyclicality of required capital. We are not aware of any evidence on whether new loans issued in a cyclical downturn tend to have better collateral and seniority protection. For non-defaulting loans from earlier cohorts, the evidence is mixed. Altman, Brady, Resti and Sironi (forthcoming) and Frye (2003) find that post-default market prices of bonds tend to be lower during a recession. We are not aware of evidence on whether there is such systematic risk in ex-post recoveries at resolution. Furthermore, loans and bonds may perform differently in this respect. Unlike bonds, loans are typically issued with covenants that allow the bank to renegotiate terms when the borrower breaches certain financial ratios. Asarnow and Edwards (1995) describe how covenant relief is often traded for better collateral protection. Araten, Jacobs, Jr. and Varshney (forthcoming) observe that $75 \%$ of troubled loans are secured, yet most of these loans were unsecured at origination. This would imply that, for many loans, an increase in assigned PD associated with a downgrade would be partly offset by a simultaneous decrease in assigned LGD.

Beyond the mechanics of the IRB formula and the behavioral response of banks to a downturn lies a larger question. To what extent will regulatory capital requirements impose a binding constraint on large banks? If large banks in the 21 st century manage themselves in accordance with economic capital, then 
Figure 1: Average Maturity of New Loans by Year of Issue

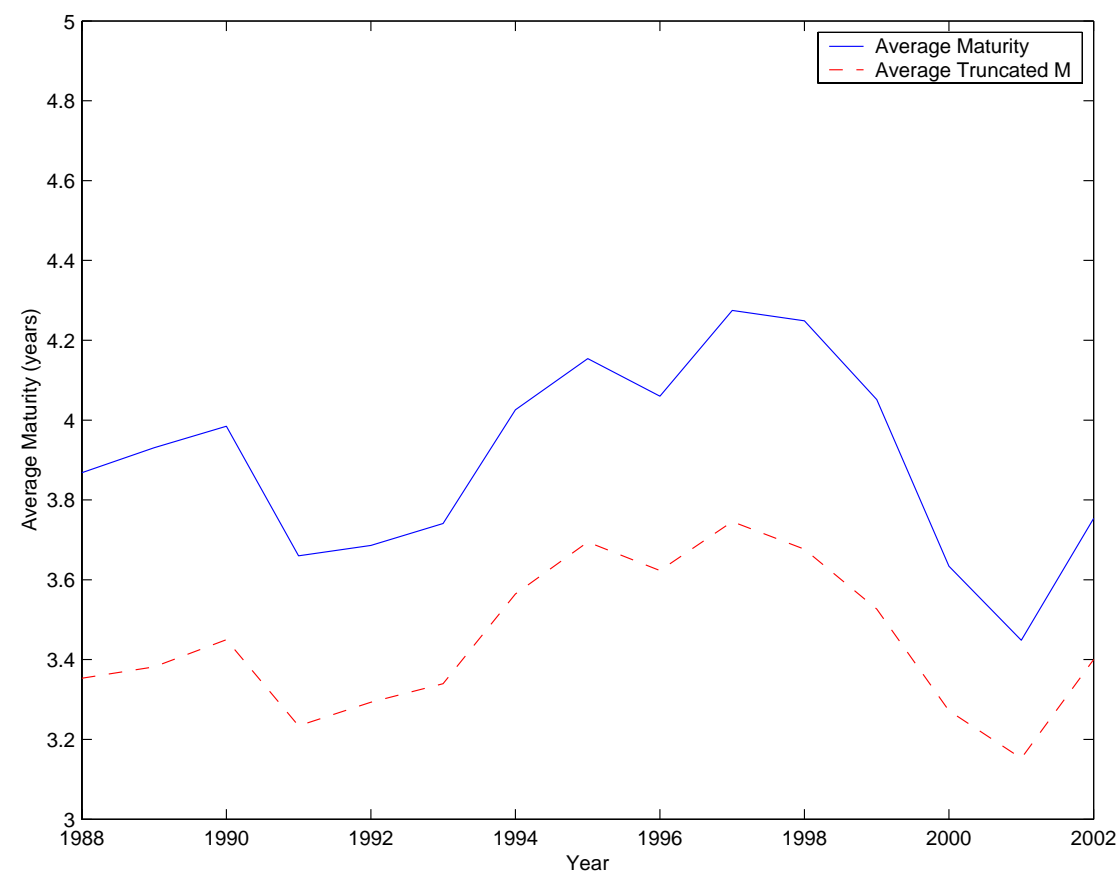

would policymakers' initiatives to smooth regulatory capital lead to any change in bank behavior over the business cycle?

In their internal capital systems, large banks typically set target solvency probabilities to at least $99.95 \%$. If the IRB capital formula is reasonably consistent with the internal VaR model, then the bank's internal capital requirement would exceed the regulatory minimum (calculated setting $q$ to $99.9 \%$ ) by $15 \%$ to $20 \%{ }^{12}$ It is often argued that a regulatory solvency target of $99.9 \%$ implies a rather higher solvency target in practice, as the bank must hold a buffer sufficient to avoid falling below the regulatory minimum in the event of a downturn (Furfine 2000). Jokivuolle and Peura (2001) model this buffer as satisfying a metaVaR requirement: the bank sets a target probability of being unconstrained by the regulatory minimum at the horizon. ${ }^{13}$ Adding this constraint significantly increases the regulation's effective one-year solvency standard. While this argument has merit, it ought to apply equally to the bank's internal economic capital calculations. At least for large international institutions, franchise value at the horizon is dependent on

\footnotetext{
${ }^{12}$ The IRB formula does embed a conservative estimate of the asset-correlation $\rho$ relative to econometric estimates using rating agency performance data (Gordy and Heitfield 2002, Düllmann and Scheule 2003, Rösch 2003). This could cause the IRB formula at a $99.9 \%$ target to overshoot economic capital at higher target solvency probabilities in some internal systems. Consultation with large banks early in the Basel reform process suggests, however, that most internal systems also impose fairly conservative correlation assumptions for commercial loan portfolios.

${ }^{13}$ Kashyap and Stein (2004) suggest instead that the buffer will be chosen so that the bank can expect to be no more capital constrained at the horizon than it is today. As a recession represents a negative surprise, they conclude that the buffer will not be very helpful in absorbing cyclical shocks. We take a different view. If the costs of "capital distress" (i.e., the regulatory counterpart to financial distress) are convex in distance to the regulatory minimum, then the buffer must indeed be chosen to protect against a worse-than-expected macroeconomic scenario.
} 
retaining a favorable agency rating. So, for example, an institution that seeks to have capital sufficient for an AA rating today (say, a one-year target solvency probability of 99.95\%) might also want to have a $95 \%$ probability of remaining investment grade at the horizon. This meta-VaR constraint creates a buffer for economic capital.

Even for those banks for which the buffer on the regulatory minimum is the binding determinant of capital, the target probability in the meta-VaR constraint need not - indeed, should not - be held constant over the business cycle. Kashyap and Stein (2004) point out that optimal capital regulation must balance the competing objectives of avoiding the social cost of bank failure against the opportunity cost of foregone positive-NPV loans. As the shadow cost of bank capital varies over the cycle, so should the optimal point in this trade-off, and so the target solvency probability in the regulatory rule ought to be time-varying. We apply the same argument to the bank's internal buffering problem. As the shadow cost of bank capital varies, so should the trade-off between the cost of future capital shortfall and the cost of foregone profit today. Empirical evidence shows that bank capital buffers do indeed vary over the cycle as predicted. Flannery and Rangan (2002) demonstrate that changes in the capital buffers held by US banks in the 1990s vary negatively with changes in the risk profile of their portfolios. ${ }^{14}$ Therefore, even if supervisors do not provide any explicit Pillar 2 guidance on buffer levels, some portion of the cyclicality in regulatory capital requirements is likely to be absorbed by time-variation in buffers held above the regulatory minimum.

\section{Simulation engine}

We construct a simulation engine to generate bank portfolios and capital requirements in a stylized economy. Two broad sets of goals shape the exercise. First, we want to assess the sensitivity of estimated procyclicality in economic capital to model assumptions on bank strategy for portfolio management. Second, we want to evaluate alternative proposals for dampening procyclicality in regulatory capital. We examine the extent to which the dampening rule would leave intact the reliability of regulatory capital in rank-ordering banks cross-sectionally and in signalling directional changes in capital strength through time.

The simulation tracks a set of $I$ stylized bank portfolios over $T$ years. There is a single "global" riskfactor representing shocks to the overall macroeconomy through time, as well as bank-specific "local" riskfactors. Each bank maintains a portfolio of $N$ equal sized corporate loans that are equal in exposure size, but heterogeneous in credit quality and remaining maturity. For each loan, we track the "true" (i.e., pointin-time) probability of default through time until maturity or default. Once these data are generated, we can emulate alternative rating schemes (such as through-the-cycle ratings) by applying an appropriate filter to the point-in-time ratings. We next calculate for each year and each bank the annual portfolio-level economic capital requirement and the annual regulatory capital minimum under CP3 and alternative proposals. For all our simulations we set $N=2000$ loans, $I=20$ banks, and $T=100$ years.

Borrower credit quality in each portfolio of loans is governed by a single-factor CreditMetrics model. Borrowers are distributed across $G$ non-default (i.e., "live") grades with grade 1 representing best credit

\footnotetext{
${ }^{14}$ They measure capital on a market-value basis. By the mid 1990s, regulatory capital arbitrage was sufficiently far along that regulatory capital itself should not have been a binding consideration for any large US bank.
} 
quality and grade $G$ worst credit quality. Grade $G+1$ denotes default. The transition process is assumed to be Markov with time-homogeneous one-year transition matrix $\bar{P}$. Associated with borrower $j$ at time $t$ is a latent variable $R_{j, t}$ that represents the performance of borrower $j$ in the interval since time $t-1$. As CreditMetrics draws its inspiration from the model of Merton (1974), $R_{j, t}$ is typically interpreted as a standardized return on the assets of the borrower. If that return is sufficiently negative, the borrower defaults. More generally, the outcome of $R_{j, t}$ determines the borrower's change in creditworthiness (and so its rating) in the interval $(t-1, t]$. For each live grade $g$, we divide the real line into $G+1$ intervals using a vector of thresholds

$$
-\infty=\gamma_{g, G+1} \leq \gamma_{g, G} \leq \cdots \leq \gamma_{g, 1} \leq \gamma_{g, 0}=\infty
$$

If borrower $j$ is in grade $g$ at time $t-1$, then its rating at time $t$ depends on the interval into which $R_{j, t}$ falls. If we assume that $R_{j, t}$ has standard normal distribution, then consistency with the given transition matrix $\bar{P}$ requires that

$$
\gamma_{g, k}=\Phi^{-1}\left(\sum_{\ell=k+1}^{G+1} \bar{p}_{g, \ell}\right)
$$

for $1 \leq g \leq G$ and $1 \leq k \leq G$, where $\Phi^{-1}$ is the inverse normal cumulative distribution function (cdf).

The implications of imposing a time-homogeneous Markov transition process are often underappreciated. The model rules out serial dependence of any form in the rating process, so the rating must be interpreted as a sufficient statistic for the one-year probability of default. Put another way, while the ex-post default frequency for a grade might vary over time, the ex-ante probability of default associated with the grade is constant. As firm-level accounting variables and macroeconomic indicators may be serially correlated, the rating system must incorporate all expected change in those variables into rating assignments, so that only unexpected shocks determine rating change over the subsequent interval. This property is the defining characteristic of a point-in-time (PIT) rating system. Equity markets filter information in much this manner, so structural default models calibrated to equity returns ought to yield (more or less) PIT ratings. The KMV model is a well-known and widely-used example, so we set $\bar{P}$ to a matrix tabulated from annual changes in KMV EDFs (Gupton, Finger and Bhatia 1997, Table 6.3). This matrix displays greater rating volatility than comparable rating agency matrices. The implication in our context is that the KMV matrix will generate much more cyclicality in capital charges than a more stable rating agency matrix.

In CreditMetrics, dependence across borrower defaults and rating migrations is generated by decomposing borrower asset-returns into a systematic component and an idiosyncratic component. We divide borrowers into sectors so that firms in the same sector share a common systematic factor. If firm $j$ is in sector $i$, then we write

$$
R_{j, t}=X_{i, t} \sqrt{\rho}+\epsilon_{j, t} \sqrt{1-\rho}
$$

where $X_{i, t}$ is the sector risk factor. The $X_{i, t}$ are distributed standard normal and serially independent, and 
the $\epsilon_{j, t}$ are i.i.d. standard normal. The so-called "asset-correlation" parameter $\rho$ determines the strength of dependence across borrowers within the same sector.

In principle, $\rho$ might vary across borrowers and even across time. One new feature introduced to the proposed New Accord in CP3 is a declining functional relationship between borrower PD and the imposed value of $\rho$ in the IRB formula (CP3, 241). This was motivated partly by the belief that smaller firms tend to be both higher in PD and lower in $\rho$ than larger firms, which would implies a negative cross-sectional correlation between PD and $\rho$. This new feature in $\mathrm{CP} 3$ also served to flatten the IRB formula relative to $\mathrm{CP} 2$, which may have been perceived as desirable for moderating procyclicality. In our simulations, we maintain the assumption of a constant $\rho=0.18$ across borrowers and across time. It is not our intention to take a strong stance on whether $\rho$ is indeed decreasing with respect to PD, as we lack data sufficient to distinguish between the $\mathrm{CP} 3$ rule and a constant $\rho$. Rather, we adopt the constant $\rho$ assumption merely to create a convenient benchmark against which to test the efficacy of the CP3 rule in reducing the volatility of regulatory capital relative to economic capital.

Finally, the model allows also for dependence across the sectors. The $X_{i, t}$ are decomposed as

$$
X_{i, t}=\sqrt{\beta_{i}} X_{t}^{*}+u_{i, t} \sqrt{1-\beta_{i}}
$$

where $X_{t}^{*}$ is a univariate factor representing the overall macroeconomy, $u_{i, t}$ is a sector specific factor, and parameter $\beta_{i} \in[0,1]$ determines the strength of dependence across sectors. As above, we assume that $X_{t}^{*}$ is distributed standard normal and serially independent, the $u_{i, t}$ are i.i.d. standard normal, and (for simplicity) that $\beta_{i}=\beta$ for all $i$. Our baseline calibration is $\beta=0.9$, but we examine the robustness to lower values of $\beta$ in Section 3.3.

In a typical practitioner implementation of this model, sector $i$ would be associated with some combination of geographic region and industrial sector. In our exercise, sector $i$ will be identified with the borrower's bank. The intuition is that bank portfolios can differ in regional or industrial sector concentrations that cause them to experience somewhat different systematic risk from other banks in the same national market. So long as there are barriers to expansion across bank markets, the bank-specific factor $X_{i, t}$ is effectively the single macroeconomic risk factor as experienced by bank $i$. The conditions of Gordy (2003) then hold, and the IRB formula for $K_{\text {irb }}$ in equation (2) provides an asymptotic approximation to the bank's internal economic capital allocation rule (for its internally measured asset-correlation $\rho$ and chosen target solvency probability $q){ }^{15}$ Of course, if $\beta=1$ then $X_{i, t}=X_{t}^{*}$ for all banks, and the model resolves to the standard single factor model associated with the New Accord.

Our motivation for introducing market segmentation is to make the regulator's problem more challenging. If we simply imposed $\beta=1$, then we would effectively be granting the regulator access to information (namely the history of $X_{\tau}^{*}$ for $\tau \leq t$, which could be estimated accurately by looking at the performance of the banking system over time) that would summarize precisely the state of the macroeconomy at time $t$ as experienced by every bank in the market. The regulator could then form a perfect counter-cyclical index and

\footnotetext{
${ }^{15}$ As our simulated portfolios are finite, there is a residual of undiversified idiosyncratic risk that contributes to VaR. The granularity adjustment introduced in $\mathrm{CP} 2$ (but eliminated in $\mathrm{CP} 3$ ) could be used to provide a correction accurate to first order in $1 / N$. See Gordy (2004) for a survey article on this technique.
} 
costlessly eliminate cyclical volatility in capital. We do not wish to assume that regulators have such perfect information. In practice, credit problems do not necessarily emerge simultaneously across all banks in the same national market, and the regulator must make do with macroeconomic indicators that are imperfectly correlated with the true conditions faced by each bank under its authority.

\subsection{Reinvestment in new cohorts of loans}

Existing studies have taken two different approaches to portfolio construction. Under one approach, the portfolio is fixed at the beginning of the simulation period. Defaulting obligors disappear and are not replaced. Under the other, the portfolio is the actual universe of rated instruments in a bank portfolio or rating agency database. Loosely speaking, the first approach measures a partial derivative of the effect of the business cycle on capital volatility, while the latter approach incorporates the portfolio's response to changing business conditions and so gives a total derivative. We have argued that this total derivative is more informative for policy purposes, but in any case want to explore the sensitivity of results to our assumptions. As a practical matter, we cannot avoid introducing some form of reinvestment behavior. Otherwise, over a long simulation period (100 years), the portfolio would shrink dramatically in size as borrowers reach the absorbing state of default.

Our reinvestment rules are built from three primitive "idealized" rules. Each idealized rule can be represented as a vector, $S$, that gives a multinomial probability function over rating grades 1 through $G$. New loans, issued at the end of year $t$ to replace all loans that matured or defaulted during that year, are drawn iid from $S$. The new loans are included in calculation of portfolio capital at time $t$ (i.e., capital held against risk at horizon $t+1$ ). The first idealized rule, which we shall refer to as "fixed" replacement, assumes that a bank maintains a consistent credit quality standard over time in its loan origination. The ratings of newly originated loans are therefore drawn from a time-homogeneous probability vector, denoted $S^{\text {fixed }}$. In our simulated economy, the same $S^{\text {fixed }}$ is applied to all banks. Table 1 shows the "average quality" and "high quality" distributions reported by Gordy (2000) for large US banks. Unless otherwise noted, we set $S^{\text {fixed }}$ to the average quality distribution.

Table 1: Fixed reinvestment rule distributions

\begin{tabular}{lccccccc} 
& AAA & AA & A & BBB & BB & B & CCC \\
\hline Average quality & $3 \%$ & $5 \%$ & $13 \%$ & $29 \%$ & $35 \%$ & $12 \%$ & $3 \%$ \\
High quality & $4 \%$ & $6 \%$ & $29 \%$ & $36 \%$ & $21 \%$ & $3 \%$ & $1 \%$ \\
\hline
\end{tabular}

The second idealized rule, which we refer to as "passive" replacement, assumes that the distribution of ratings across surviving loans in its portfolio at the end of period $t$ is representative of the bank's lending opportunities. The distribution associated with this rule, $S_{i, t}^{\text {survive }}$, is therefore simply given by the frequency distribution of ratings in the non-defaulted portion of the existing portfolio of bank $i$ at the end of period $t$. Under this rule, reinvestment does not alter the overall distribution of ratings within each portfolio, so it generates behavior similar to the passive management strategy of Kashyap and Stein (2004) and Rösch 
(2002).

The third idealized rule, which we refer to as "cyclical" replacement, assumes that bank lending "leans against the wind." That is, banks tighten standards in a recession and loosen standards in an expansion. A simple and flexible mechanism for implementing this notion starts with a vector of baseline thresholds that divide the real line into $G$ intervals:

$$
-\infty=\zeta^{*}(0) \leq \zeta^{*}(1) \leq \cdots \leq \zeta^{*}(G-1) \leq \zeta^{*}(G)=\infty
$$

The baseline thresholds are transformations of the average quality $S^{\text {fixed }}$ probability vector. Similar mechanically (though not in any substantive sense) to the CreditMetrics methodology, we set

$$
\zeta^{*}(g)=\Phi^{-1}\left(\sum_{k=1}^{g} S^{f i x e d}(k)\right)
$$

for $1 \leq g \leq G-1$. Next we form a vector of cyclically-shifted $\zeta_{i, t}$ thresholds which determine $S_{i, t}^{c y c l i c a l}$ as

$$
S_{i, t}^{c y c l i c a l}(g)=\Phi\left(\zeta_{i, t}(g)\right)-\Phi\left(\zeta_{i, t}(g-1)\right)
$$

When $X_{i, t-1}$ is negative (positive), bank $i$ has just experienced a negative (positive) macroeconomic shock. In response, we to shift probability mass to the higher (lower) quality grades by setting

$$
\zeta_{i, t}^{\text {cyclical }}(g)=\frac{\zeta^{*}(g)-\delta \cdot X_{i, t-1}}{\sqrt{1-\delta^{2}}}
$$

where $\delta \in[0,1]$ controls the sensitivity of $\zeta^{\text {cyclical }}$ to the bank's macroeconomic environment (we set $\delta=0.1)$.

A wide variety of plausible reinvestment rules can be generated as weighted combinations of the idealized rules. For example, the findings of Bassett and Zakrajšek (2003) suggest that some portion of new lending is determined by pre-existing relationships, but that the bank cyclically tightens and loosens standards for lending to new customers. We therefore specify a "Bassett/Zakrajšek" (BZ) reinvestment rule as a weighted average of the passive and cyclical rules:

$$
S_{i, t}^{B Z}=\omega \cdot S_{i, t}^{\text {survive }}+(1-\omega) \cdot S_{i, t}^{\text {cyclical }}
$$

For simplicity, we set the weight parameter $\omega$ to $1 / 2$.

In order to ease comparison of results across reinvestment rules, our simulation engine first draws the global systematic factor $\left(X_{t}^{*}\right)$ and the bank-level systematic factors $\left(X_{i, t}\right)$ for each bank and time period. Holding these histories fixed, we draw for each bank the individual borrower histories generated under each reinvestment rule. Thus, bank portfolios are exposed to the same systematic shocks across simulation runs that differ in reinvestment rules. In all simulations, regardless of the reinvestment rule, we draw ratings in the initial portfolio at the beginning of the simulation $(t=0)$ from the $S^{\text {fixed }}$ distribution. To dilute 
sensitivity of our results to initial conditions, we drop from our time series the first $T_{\text {burn }}$ years. That is, we run each simulation for $T_{\text {burn }}+T$ years and then drop the first $T_{\text {burn }}$ years. We set $T_{\text {burn }}=40$.

In principle, we could develop a variety of rules to govern the assignment of LGD and initial maturity to new loans. We draw a random initial maturity for each new loan such that $(M-1)$ is distributed Poisson with mean parameter $\phi$. We presented evidence in Section 1 that $\phi$ might vary cyclically. Evidence in Berger, Espinosa-Vega, Frame and Miller (2003) suggests that $\phi$ should vary across the initial grade of the loan as well. The simulation has enough "moving parts" as is, so for simplicity we impose a uniform value of $\phi=1.5$ across all new loans at all times. This implies a mean initial maturity of 2.5 years in each cohort. For LGD, we impose the CP3 Foundation approach assumption of a constant $45 \%$ of face value (CP3, Ф250).

\subsection{Through the cycle ratings}

Credit ratings provided by external rating agencies such as Moody's and S\&P are often characterized as through-the-cycle (TTC) by market participants, academics and the agencies themselves. These ratings tend to be more stable over time than the PIT ratings generated by KMV and most bank internal systems. So long as the PDs assigned to each grade are estimated by taking long-run average default frequencies, stable rating assignments imply stable PD assignments, and so diminish capital volatility. For this reason, CatarineuRabell et al. (2003) recommend that regulators encourage banks to adopt TTC systems in order to mitigate procyclicality. ${ }^{16}$

Despite the ubiquity of the term "through the cycle" in descriptions of rating methods, there seems to be no consensus on precisely what is meant. The agencies own documentation describes a set of qualitative and sometimes conflicting objectives in their rating processes. One view is that TTC ratings in some way "filter out" changes in the state of the business cycle from changes observed in borrower creditworthiness. Carey and Hrycay (2001) find evidence in agency ratings that TTC systems assign rating based on the borrower's likelihood of survival in the event of a macroeconomic stress scenario. Because the stress scenario is fixed, the current state of the macroeconomy is irrelevant. Another view is that TTC ratings are simply long-term ratings. Altman and Rijken (forthcoming) find that agency ratings and PIT models perform comparably in predicting default over a six year horizon. To explain this result, the model of Löffler (2004) assumes that firm asset values are subject to both permanent and transitory shocks, but TTC ratings react to only the permanent shocks. By filtering out the transitory shocks, TTC systems also avoid rating reversals, which the agencies acknowledge as a goal. Cantor (2001) reports that Moody's attempts to assign ratings so as to minimize "abrupt changes in rating levels" and as such "a rating action is taken only when it is unlikely to be reversed within a relatively short period of time." Altman and Rijken (forthcoming) suggest that agencies wait until the "appropriate" rating predicted by the agency's model differs from the borrower's current rating by a certain amount before they adjust a borrower's rating, and, even then, the rating is only

\footnotetext{
${ }^{16}$ Of course, as demonstrated by Heitfield (2004), the long-run average default frequency will in general not be the best estimate for a TTC grade's one-year default probability given contemporaneously observable information on the state of the macroeconomy. Like a clock stuck at twelve o'clock, the long-run average default frequency will align with the optimal full-information estimate of PD roughly twice per business cycle.
} 
partially adjusted. Löffler (2002) and Wong and Chan (2002) offer formal models in this vein; see also Christensen, Hansen and Lando (forthcoming) for a slightly different interpretation.

We do not propose to reconcile these characterizations into a single model. Rather, we focus on the view that "the prime objective of [rating] agencies is to provide an accurate relative (i.e., ordinal) ranking of credit risk at each point in time" (Cantor and Mann 2003). This objective is satisfied by a rating scheme that sorts borrowers in the economy by their one-year probability of default. ${ }^{17}$ At the beginning of period $t$, all $N \times I$ "live" borrowers in the rated universe are sorted according to PIT rating (by descending credit quality). The ordinal scheme assigns the top fixed share $S_{1}^{\text {ord }}$ of the borrowers to grade 1 , the next share $S_{2}^{\text {ord }}$ to grade 2 , and so on. The implication is that the number of borrowers assigned to each grade is time-invariant for the economy as a whole, but the distribution within each bank is free to vary. ${ }^{18}$ For simplicity, we set the $S^{\text {ord }}$ vector equal to the $S^{\text {fixed }}$ vector.

After borrowers are assigned TTC ratings for each year in the simulation, we calculate the average PIT default probability (across time and borrowers) for each ordinal grade. Our "CP3-TTC" capital rule merely substitutes into the IRB formula the "time-averaged PD" associated with the borrower's TTC rating grade in place of the borrower's "true" PIT PD.

\subsection{Smoothing the regulatory minimum}

Our primary objective in the simulations is to explore the behavior of smoothing rules that are applied directly to the output of an unmodified IRB capital function. Assume that bank rating systems are point-intime, and let $C_{i t}$ denote the unsmoothed output from the IRB capital formula for the portfolio of bank $i$ at time $t$, expressed as a percentage of portfolio book value. One simple method for generating a smoothed regulatory requirement $\hat{C}_{i t}$ from the $C_{i t}$ is to apply an autoregressive (AR) filter:

$$
\hat{C}_{i, t}=\hat{C}_{i, t-1}+\alpha \cdot\left(C_{i, t}-\hat{C}_{i, t-1}\right)
$$

where $\alpha$ is an adjustment parameter that controls the degree of smoothing. We set $\alpha=0.25$ in our simulations. ${ }^{19}$ The intuition is that shocks to $C_{i t}$ are absorbed into the regulatory minimum over several years, rather than all at once.

A second approach to smoothing the output is counter-cyclical indexing. Under a "CC smoothing" rule, the national regulator in each period announces a multiplier $\alpha_{t}$. The regulatory minimum is then expressed as $\hat{C}_{i t}=\alpha_{t} C_{i t}$. The same multiplier applies to every bank in the regulator's jurisdiction. In the context of

\footnotetext{
${ }^{17}$ In our homogeneous model, every rating horizon implies the same sorting, so it is meaningless to distinguish between shortterm and long-term ratings.

${ }^{18} \mathrm{We}$ also explored an alternative ordinal scheme in which borrowers were sorted within each bank rather than across the rated universe. Not surprisingly, capital requirements were perfectly smooth and completely uninformative both across time and across banks.

${ }^{19}$ As a starting condition, we also impose $\hat{C}_{i t}=C_{i t}$ at $t=0$. As the first 40 years are discarded as a "burn-in" period, this assumption does not influence our results.
} 
our model, we specify the multiplier as

$$
\alpha_{t}=\exp \left(a \cdot\left(\omega_{1} X_{t-1}^{*}+\omega_{2} X_{t-2}^{*}+\ldots+\omega_{k} X_{t-k}^{*}\right)-a^{2} / 2\right)
$$

where the lag weights satisfy $\omega_{1}^{2}+\omega_{2}^{2}+\ldots+\omega_{k}^{2}=1$. We use $k=1$ or $k=2$ lags in our simulations. Parameter $a$ controls the degree of smoothing. To calibrate, let $V_{\alpha}$ denote the desired unconditional variance of the multiplier across time (we set $V_{\alpha}=0.01$ ). Setting $a=\sqrt{\log \left(1+V_{\alpha}\right)}$ implies $\operatorname{Var}\left(\alpha_{t}\right)=V_{\alpha}$ as desired. The $a^{2} / 2$ term in equation (11) guarantees that $\mathrm{E}\left[\alpha_{t}\right]=1$.

As an alternative to a time-varying multiplier, we could adopt a time-varying target solvency probability (i.e., $q_{t}$ in place of $q$ in CP3). Kashyap and Stein (2004) suggest that this is a natural and intuitive policy lever for optimal capital regulation when the opportunity cost of foregone positive-NPV loans can change relative to the social cost of bank failure. A simple way to implement this in our simulation would be

$$
q_{t}=\Phi\left(\Phi^{-1}(0.999)+\alpha X_{t-1}^{*}\right)
$$

We call this rule "time-varying $q$ " (TVQ). Despite the appeal of the TVQ rule to economic intuition, it would be somewhat cumbersome to implement. Although it appears explicitly in the IRB formula only in the $V(\mathrm{PD}, \rho, q)$ term, $q$ plays an implicit role in the maturity adjustment as well (i.e., the calibration of the $b(\mathrm{PD})$ formula in the maturity adjustment is sensitive to $q$ ). More importantly, the effect of a change in $q$ on loan-level capital charges depends on borrower PD and loan type (because different rules for $\rho$ are applied to different loan portfolios). Even though $q_{t}$ would be public information, market participants would be unable to decompose a change in a bank's reported regulatory capital ratio into the change due to changes in portfolio composition and the change due to change in $q_{t} \cdot{ }^{20}$ Under the CC proposal, by contrast, the IRB capital formula does not change over time. As long as the multiplier $\alpha_{t}$ is announced by the regulator, it is trivial for market participants to back out a consistent time series of capital ratios from disclosures already specified in $\mathrm{CP} 3 .^{21}$

\section{Results}

\subsection{Reinvestment rules and portfolio quality}

We begin with a question that has not yet been formally addressed in the procyclicality literature: How sensitive are our estimates of capital volatility to the assumptions governing portfolio management over time? Figure 2 plots the time-series of economic capital (for $q=0.999$ ) needed by a single representative bank under the four different reinvestment rules defined in Section 2.1. Recall that all four histories are generated

\footnotetext{
${ }^{20}$ Banks could of course be required or encouraged to calculate portfolio capital requirements under both a fixed baseline $q$ (for market disclosure) and a time-varying $q_{t}$ (for regulatory purposes). Market transparency would then be restored, but at some cost in operational burden on banks. As is, much public commentary is directed at the perceived operational complexity of the New Accord.

${ }^{21}$ The current and New Basel specify rules not for the calculation of capital, but rather for the calculation of total risk-weighted assets (RWA). Capital is set to $8 \%$ of RWA. Under the CC proposal, but not the TVQ variant, reported RWA would retain a consistent interpretation over time.
} 
using the same draws of the global systematic factor and bank-specific systematic factor, so simulation noise is negligible in this comparison. Under a "fixed" reinvestment rule, which draws new loans from the timeinvariant distribution $S^{\text {fixed }}$, economic capital ranges from $4 \%$ to $8 \%$. As might be expected, capital under "cyclical" reinvestment is slightly less volatile than under the fixed rule and the least volatile of the rules we explored. Assuming "passive" portfolio management produces very much the largest changes in economic capital over time (a range of $2.7 \%$ to $13.7 \%$ ). Finally, the "BZ" rule results in capital with moderate volatility relative to the other rules. Economic capital under this rule generally falls between that of the "cyclical" and "passive" rules. This result is unsurprising, as BZ is defined as a weighted combination of these two rules. The same ordering is seen in summary measures of capital volatility across time. For each bank, we take the standard deviation across time of economic capital. Volatility, reported in Table 2, is the mean across banks of this standard deviation. We find that passively managed portfolios have well over twice the volatility of portfolios with "fixed" reinvestment. The mean capital charge is also much higher under the passive rule, because the portfolio is more likely to accumulate low quality borrowers. Even relative to the higher mean (last column), volatility is much higher under passive reinvestment than under the other reinvestment rules.

Figure 2: Effect of Reinvestment Rule on Capital Volatility

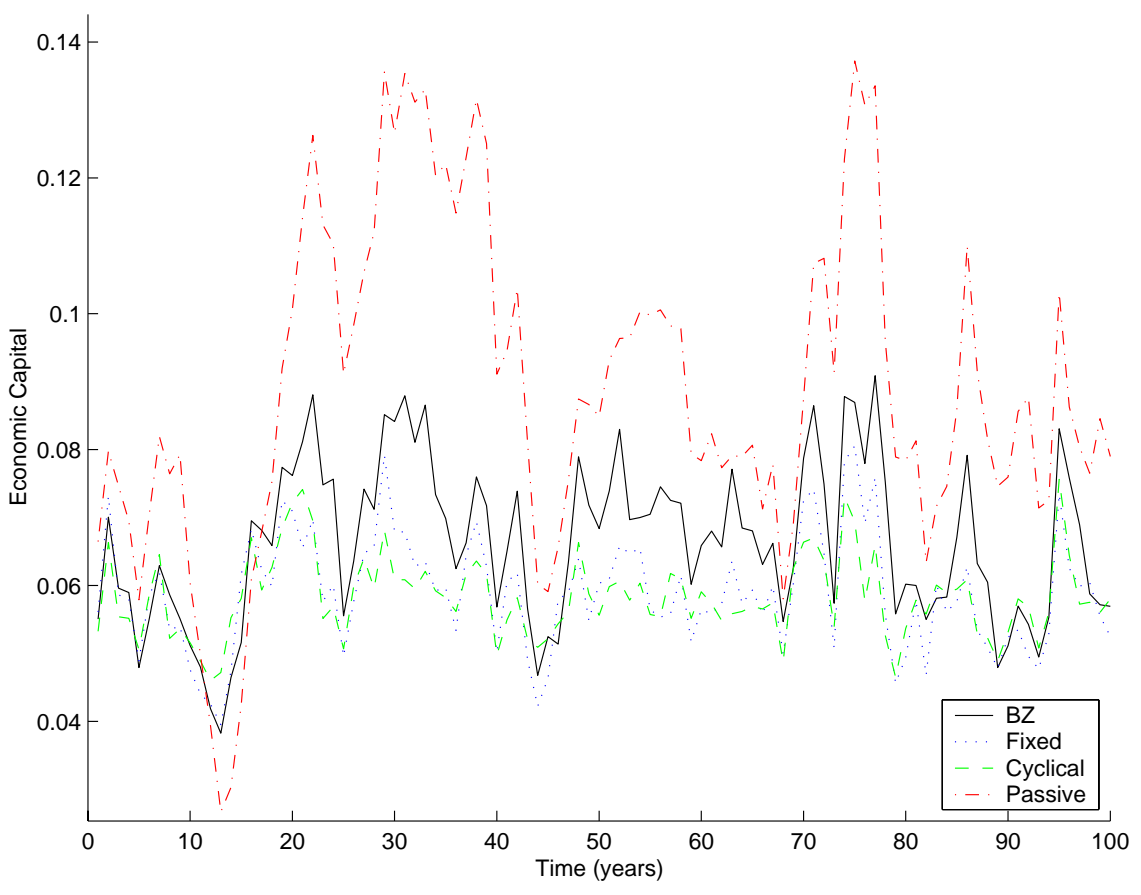

Comparisons across simulated portfolios of differing quality by Kashyap and Stein (2004), CatarineuRabell et al. (2003), and others all indicate that higher quality portfolios are subject to larger relative swings in capital requirements. We address the issue by examining the how volatility changes when we calibrate $S^{\text {fixed }}$ to the high quality portfolio in Table 1 instead of the average quality portfolio. ${ }^{22}$ As seen in Table

\footnotetext{
${ }^{22}$ The rating histories for each quality distribution are generated under the BZ reinvestment rule which is sensitive to $S^{\text {fixed }}$ through $S^{\text {cyclical }}$.
} 
Table 2: Effect of Reinvestment Rule on Capital Volatility

\begin{tabular}{|lccc|}
\hline Reinvestment Rule & Mean Capital Charge & Volatility & Volatility/Mean \\
Cyclical & $5.86 \%$ & $0.60 \%$ & 0.102 \\
Fixed & $5.90 \%$ & $0.80 \%$ & 0.136 \\
BZ & $6.63 \%$ & $1.12 \%$ & 0.169 \\
Passive & $8.80 \%$ & $2.24 \%$ & 0.255 \\
\hline
\end{tabular}

3, the high quality portfolio has a lower mean capital charge, as expected, but roughly the same absolute capital volatility. Relative to the mean capital charge, the high quality portfolio experiences slightly higher capital volatility.

Table 3: Effect of portfolio quality on economic capital volatility

\begin{tabular}{|lccc|}
\hline Portfolio Quality & Mean Capital & Volatility & Volatility/Mean \\
Average & $6.53 \%$ & $0.90 \%$ & 0.14 \\
High & $5.22 \%$ & $0.88 \%$ & 0.17 \\
\hline
\end{tabular}

Our simulations demonstrate that technical assumptions imposed on the management of bank portfolios over time have a first-order effect on the extent of procyclicality in economic capital. Sensitivity to overall portfolio credit quality, which has been noted often in the literature, is quite modest relative to sensitivity to reinvestment rules.

All remaining simulations will impose the BZ reinvestment rule, and $S^{\text {fixed }}$ will be calibrated to the average quality portfolio in Table 1.

\subsection{Rating Through-the-Cycle and flattening the capital formula}

We next evaluate the efficacy of TTC rating systems in dampening procyclicality and the associated costs to the reliability of the IRB capital requirement as a measure of portfolio risk. We similarly compare the costs and benefits associated with the modest flattening of the capital curve in CP3 that followed from introducing a negative relationship between PD and $\rho$.

In Figure 3, we plot the capital requirement time-series for a representative bank. The solid line represents CP3 capital requirements under PIT rating, and the dashed line is the corresponding CP3 capital under TTC rating. The CP3-TTC time-series displays only a small portion of the capital volatility of the CP3-PIT time-series. Observe, however, that directional changes in CP3-TTC appear to be uncorrelated with directional changes in CP3-PIT. The opposite conclusion is drawn from comparing economic capital (dotted line) with CP3-PIT. Falsely imposing a negative relationship between PD and $\rho$ when the "true" relationship (in the simulation) is constant brings about only a modest dampening of procyclicality. ${ }^{23}$ The sharpest

\footnotetext{
${ }^{23}$ We emphasize again that we are not taking any position on the empirical validity of the proposal formula for $\rho(\mathrm{PD})$ in $\mathrm{CP} 3$. The proposed formula is "false" only in the context of our simulation.
} 
peaks and troughs in the economic capital time-series are blunted in the CP3-PIT series. Otherwise, the two series track very closely, which suggests that little harm is done to the CP3-PIT capital requirement as a signal for changes in portfolio risk over time.

Figure 3: Dampening capital volatility with TTC ratings

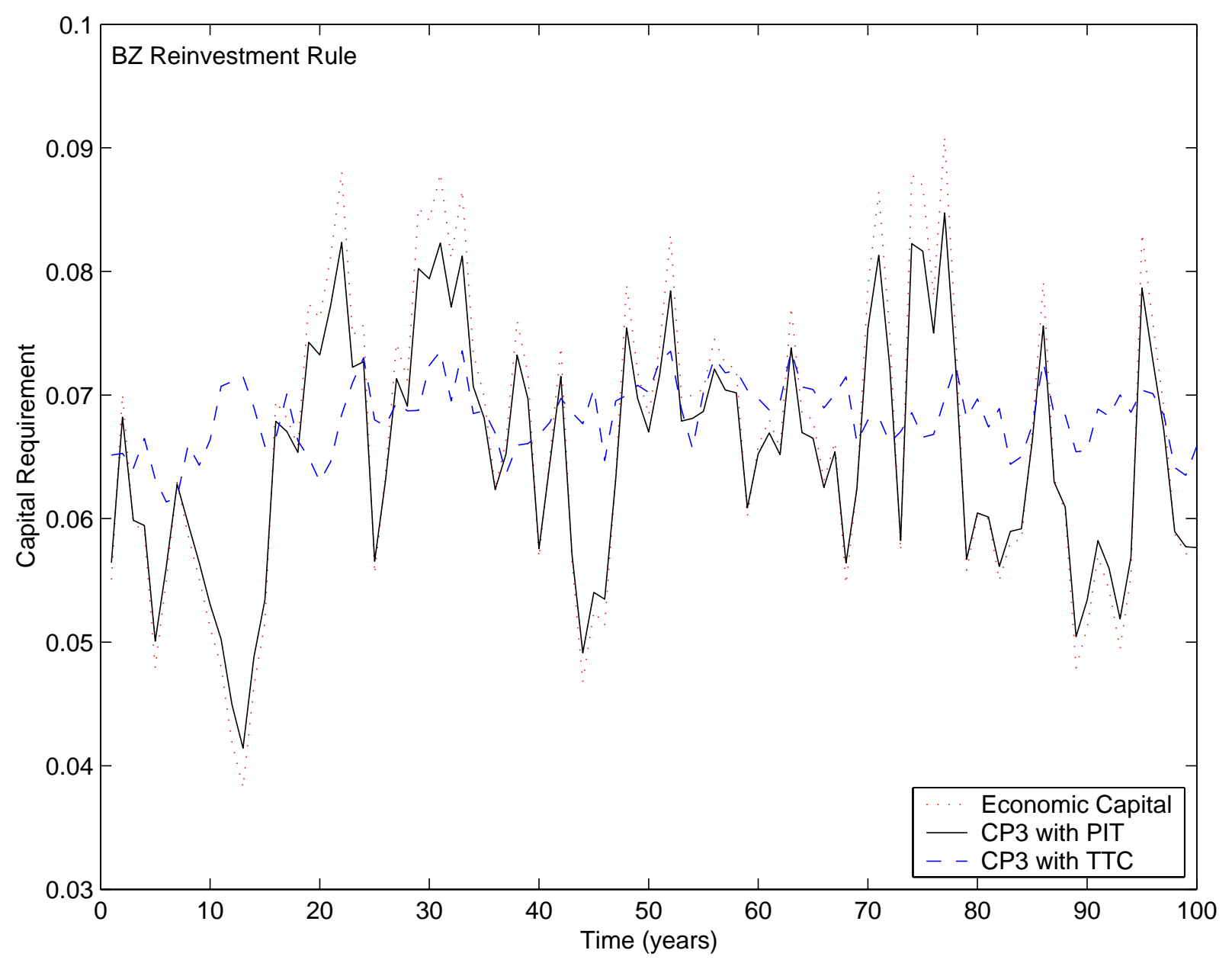

The intertemporal concordance between the three time series is best displayed by plotting the series against one another as scatterplots. In Figure 6, we plot CP3-PIT capital requirements against CP3-TTC capital requirements. We plot all points in the time-series for three representative banks (the banks are distinguished by using three different marker symbols). We see the efficacy of TTC rating as a dampening measure in the horizontal compression of the plot. The range of realized CP3-PIT capital requirements spans six percentage points, while the range of realized CP3-TTC capital requirements spans less than two percentage points. However, we also find little discernible correlation between the CP3-PIT and CP3TTC capital requirements. The CP3-PIT measure is almost perfectly correlated across time with economic capital, so we can conclude that market participants would not be able to draw reliable inferences on changes in portfolio risk from observing changes over time in disclosed CP3-TTC capital requirements. 
Figure 4: Intertemporal concordance of capital under PIT and TTC rating schemes

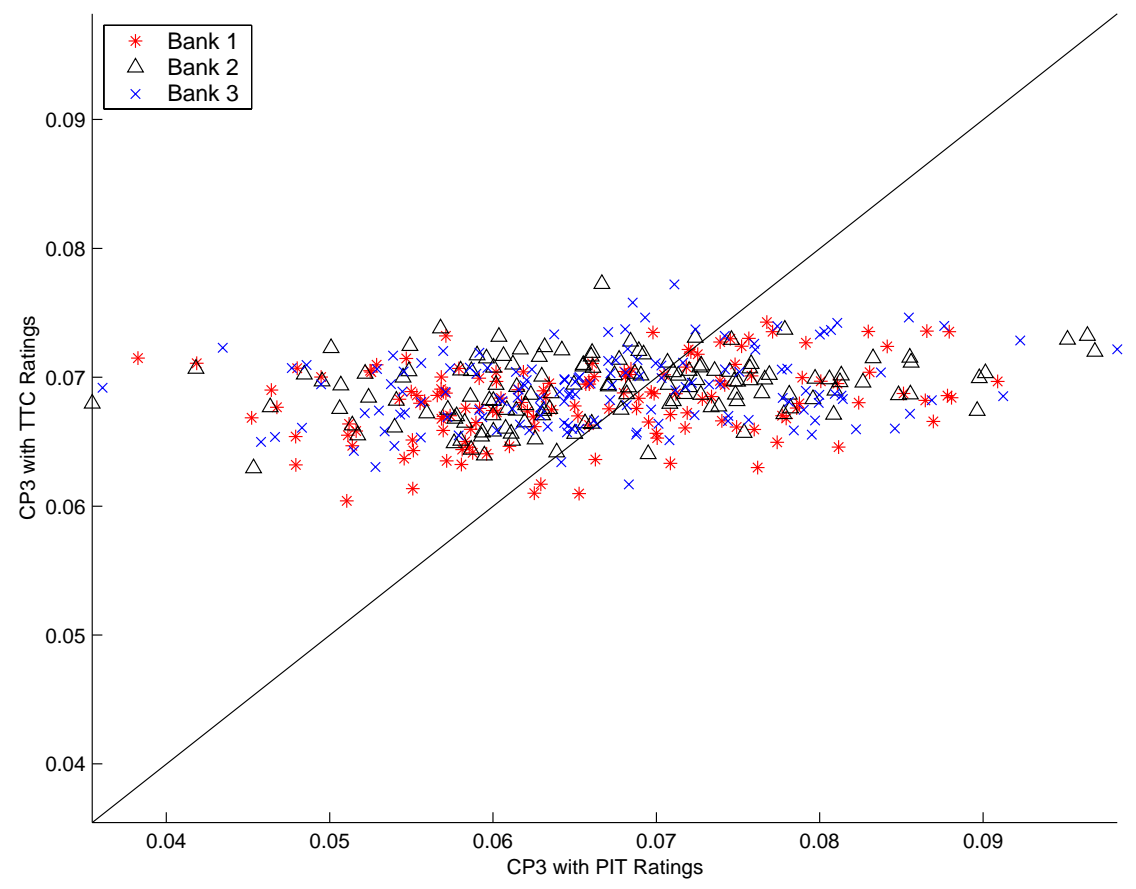

A similar scatterplot for the relationship between CP3-PIT and economic capital requirements is seen in Figure 4. Again we see the stark contrast with the properties of TTC smoothing. Relative to the economic capital benchmark, a modest dampening of volatility is achieved by reducing (increasing) capital charges on high (low) risk portfolios. ${ }^{24}$ The two time-series are almost perfectly co-monotonic, which implies that a market participant could precisely infer economic capital requirements from disclosed CP 3 requirements (when the bank maintains a PIT rating system). Therefore, there is no cost to the information value in Pillar 3 disclosures.

For purposes of cross-bank comparison at a fixed moment in time, TTC systems do not perform badly. For each of three representative years, we plot in Figure 6 the cross-sectional relationship between CP3-PIT and CP3-TTC. ${ }^{25}$ Looking across banks within a given year, we see a clear positive relationship between CP3-TTC and CP3-PIT. The intuition is that, by construction, TTC ratings preserve the ordering across firms throughout the economy in PIT rating, so typically ought to preserve the ordering across portfolios of those firms.

\footnotetext{
${ }^{24}$ The degree of dampening is revealed geometrically in the rotation of the plotted relationship relative to the $45^{\circ}$ line. Near the mean economic capital requirement of $6.63 \%$, an increase in economic capital of $1 \%$ is associated with an increase in regulatory capital of $0.85 \%$.

${ }^{25}$ We select one good year, one bad year, and one average year. A year $t$ is considered begin in a "good" ("bad") environment if it follows upon a large positive (negative) shock $X_{t-1}^{*}$ to the macroeconomy.
} 
Figure 5: Intertemporal concordance of CP3-PIT with economic capital

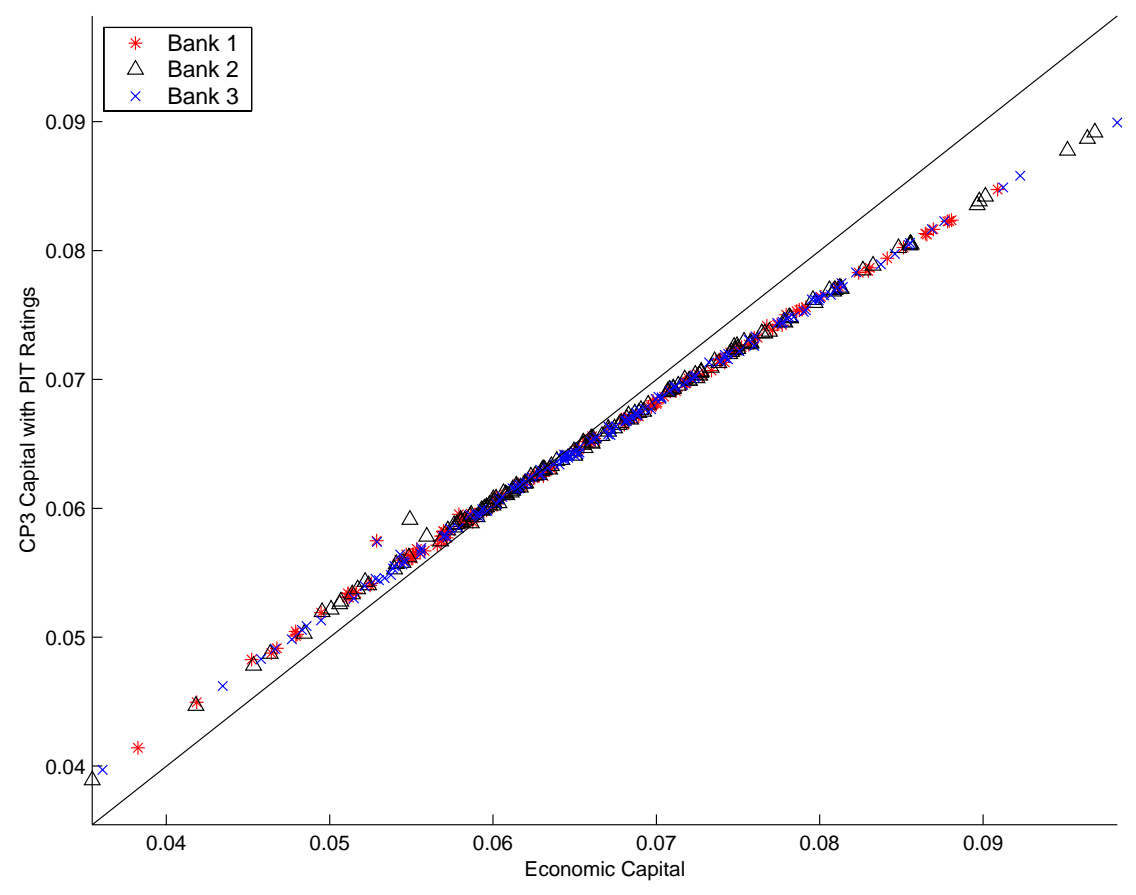

Figure 6: Cross-sectional concordance of capital under PIT and TTC rating schemes

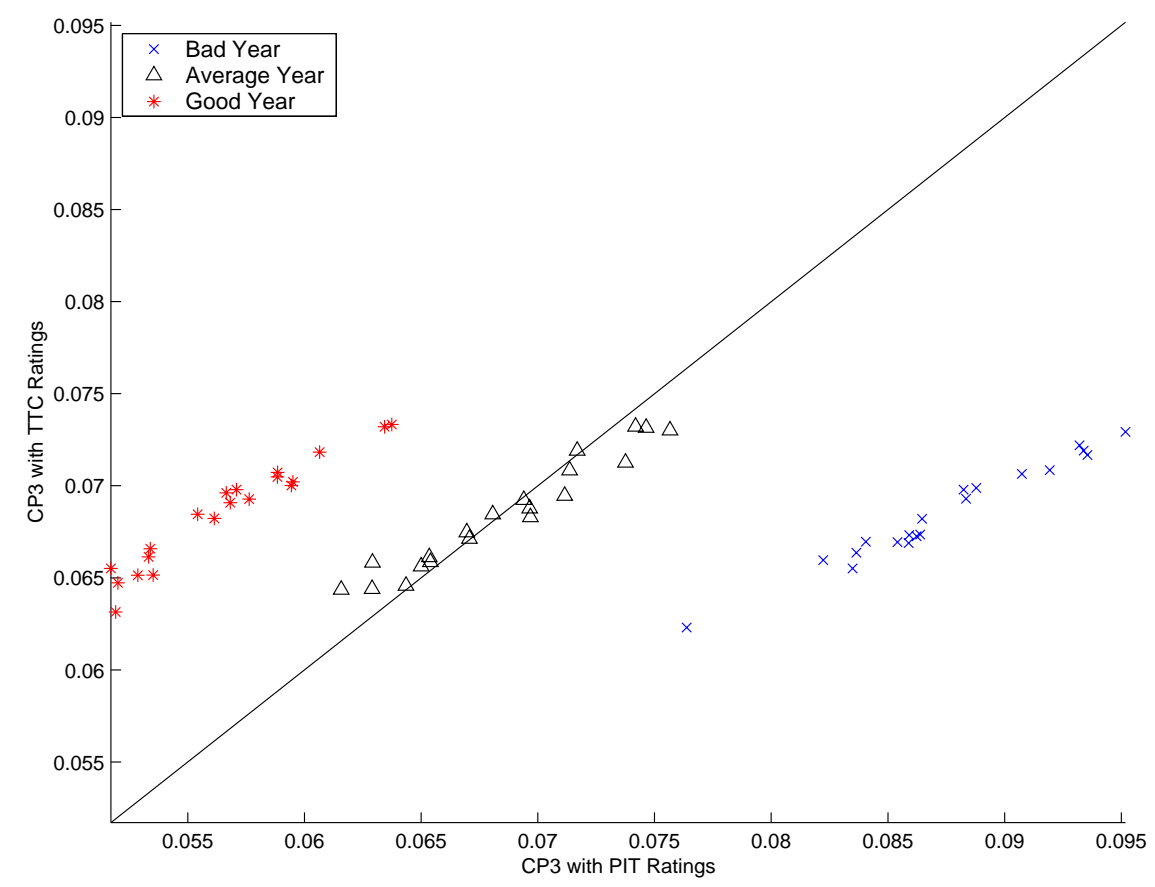




\subsection{Smoothing the regulatory minimum}

Our final task is to evaluate the efficacy of our proposed autoregressive and counter-cyclical indexing rules in dampening procyclicality. In Figure 7, we plot capital requirement time-series for a representative bank. The solid line represents CP3 capital requirements under PIT rating. The dashed and dotted lines are the corresponding CC smoothed and AR smoothed capital requirements, respectively. ${ }^{26}$ The two smoothing rules perform similarly. Each tracks CP3 capital reasonably well but with much less volatility. The average (across banks) of the standard deviation of regulatory capital across time is $0.90 \%$ for CP3-PIT, and only $0.53 \%$ and $0.46 \%$ for the AR and CC smoothing rules, respectively. The average correlation between AR smoothed capital and CP3-PIT is 0.73 , and the average correlation between CC smoothed capital and CP3-PIT is 0.72. If we examine scatterplots for the AR amd CC smoothing rules comparable to Figure 4,

Figure 7: Smoothing rules for regulatory capital

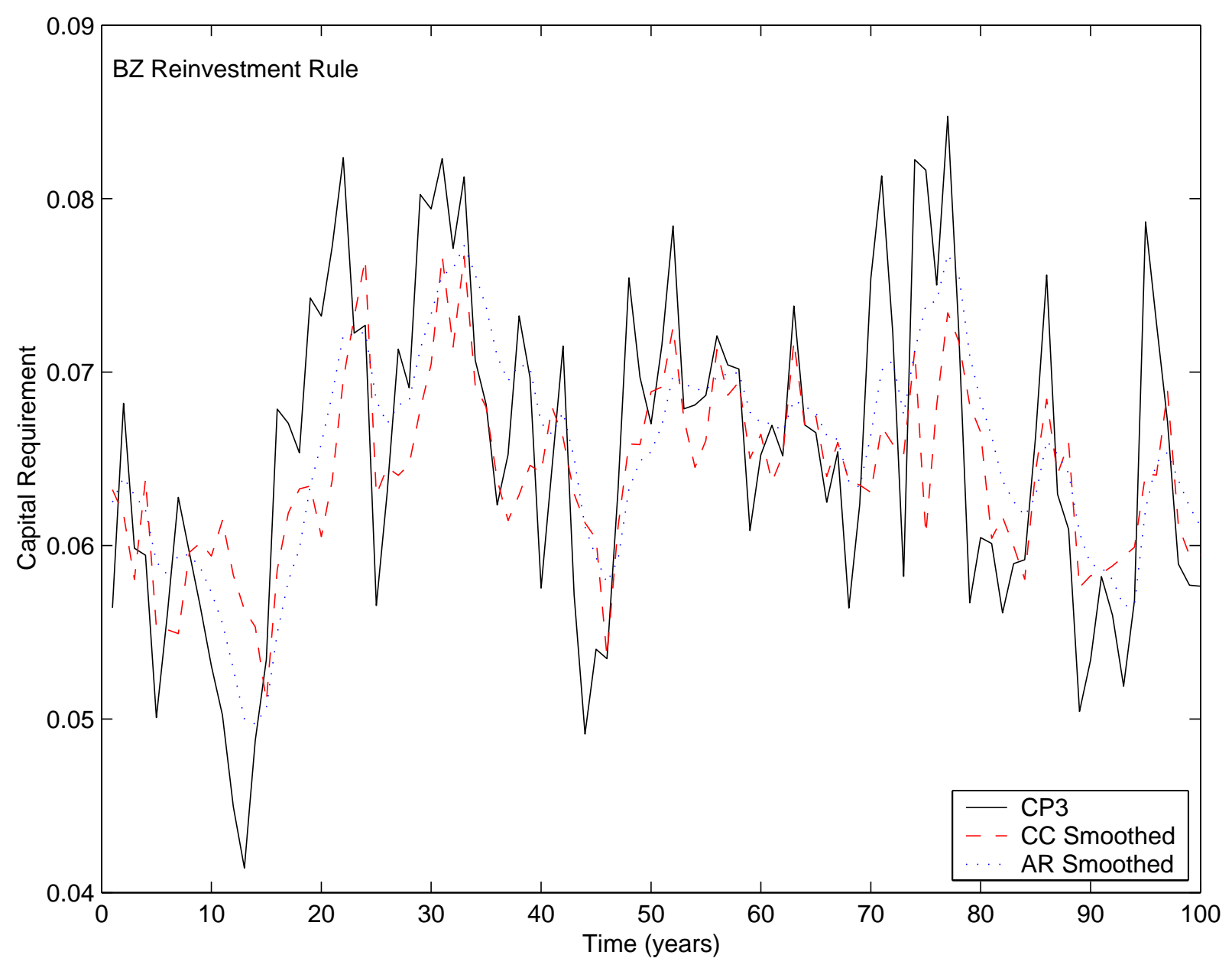

\footnotetext{
${ }^{26}$ The multiplier $\alpha_{t}$ in the CC smoothing rule is set to $\alpha_{t}=\exp \left(a \cdot\left(0.8 \cdot X_{t-1}^{*}+0.6 \cdot X_{t-2}^{*}\right)-a^{2} / 2\right)$ for $a=0.066$. Two lags of $X^{*}$ are needed to smooth reliably when we use the BZ reinvestment rule, because the "passive" component in $S^{B Z}$ induces a long memory effect. If we use the "fixed" reinvestment rule, portfolio dynamics are simplified and we find that a single lag of $X^{*}$ suffices.
} 
we see an obvious positive slope. This shows that AR smoothed and CC smoothed capital requirements would retain significant information value for use in monitoring a bank across time. Cross-sectional ordering is perfectly preserved under $\mathrm{CC}$ smoothing by construction, and reasonably well preserved under AR smoothing. From a Pillar 3 perspective, however, these questions are irrelevant, because the unsmoothed CP3 capital requirements for each bank can be easily calculated from public information. Therefore, we omit these scatterplots for brevity.

For counter-cyclical indexing to work well, the $\mathrm{CC}$ multiplier $\alpha_{t}$ must have a large negative correlation with the unsmoothed CP3 capital $C_{i t}$ for the individual banks. Indeed, if $\alpha_{t}$ and $C_{i t}$ were independent, then the "smoothing rule" would only add noise, and the variance of $\hat{C}_{i t}$ across time would exceed that of $C_{i t}$. The multiplier is set by the regulator at the national level, so depends only on the "global" systematic factor $X^{*}$. Portfolio performance for bank $i$, however, depends on the local factor $X_{i t}$. Conditional on $X_{i t}, C_{i t}$ is independent of $X_{t}^{*}$. Therefore, the correlation between $\alpha_{t}$ and $C_{i t}$ depends on the correlation between $X_{t}^{*}$ and $X_{i t}$, which is equal to $\sqrt{\beta}$. By contrast, the AR smoothing rule depends only on the current and lagged values of the bank's own $\mathrm{CP} 3$ and smoothed regulatory requirements, and so is robust to lower values of $\beta$. In our baseline calibration of $\beta=0.9$, we are assuming a reasonably close alignment between the global and local risk-factors. When we set $\beta=0.5$ in our simulations, we find that average standard deviation of regulatory capital across time is $0.96 \%$ for CP3-PIT, and $0.59 \%$ and $0.73 \%$ for AR and CC smoothing rules, respectively. Relative to the case of $\beta=0.9$, volatilities of CP3-PIT and the AR smoothing rule are roughly unchanged, but the volatility of $\mathrm{CC}$ smoothed capital increases markedly. ${ }^{27}$

\section{Discussion}

The pure simulation approach employed in this paper offers a complementary perspective on the data-driven methodologies of earlier studies of procyclicality. What our approach might sacrifice in fidelity to empirical experience, it gains from greater flexibility and precision. We can explore the consequences of alternative rating philosophies and lending strategies in a controlled environment, and draw panels of simulated data large enough to eliminate sampling variation from the results.

Our simulations make clear that the extent of cyclicality in capital requirements depends quite strongly on how new lending varies with macroeconomic conditions. Our methodology does not allow rules for new lending (what we term the reinvestment strategy) to be endogenous to the bank's capital position. This, as Kashyap and Stein (2004) argue, would defeat the purpose of the exercise. Rather, we allow the reinvestment rule to depend exogeneously on the bank's macroeconomic environment. If we are interested in identifying the marginal increment to procyclicality associated with shifting from the current Accord to a New Accord, then the current response of new lending to macroeconomic shocks is the correct benchmark. We find that empirically realistic reinvestment rules reduce procyclicality dramatically when compared to the passive portfolio strategy imposed by Kashyap and Stein (2004).

We remain somewhat skeptical that procyclicality in the New Accord indeed requires corrective measures. The existing literature already shows a wide range of empirical estimates on the magnitude of the

\footnotetext{
${ }^{27}$ Correlations between $\mathrm{CP} 3$ and smoothed capital do not change significantly for either AR or CC.
} 
problem. Our simulations confirm and extend these results in demonstrating the sensitivity of one's conclusions to assumptions imposed in the simulation. Furthermore, there is as yet no evidence on the extent to which regulatory capital (as opposed to bank's internal economic capital) will be the binding constraint for banks. Even if regulatory capital is smoothed by one means or another, procyclicality in economic capital requirements cannot be dampened by regulatory fiat.

Despite our skepticism, we believe that the need to evaluate alternative proposals is pressing. In the absence of some consensus on policy options, national regulators may pursue their own informal measures (such as encouragement of through-the-cycle rating methodologies). This may have competitive implications, as well as implications for cross-jurisdiction comparison of disclosed regulatory capital ratios. Our simulation strategy is especially well-suited to evaluating the costs and benefits of competing proposals under a wide variety of model assumptions.

Consider the New Accord as an engineering system. If we are concerned about excess volatility, where do we place the dampening filter? Some proposals call for dampening the inputs (that is, the PDs), some call for modifying the machinery (that is, by flattening the capital formula), and some call for dampening the outputs (that is, by loosening the relationship between the IRB capital formula and the required regulatory minimum). Our simulations confirm our intuitions on the strengths and drawbacks associated with each class of proposals. Dampening the inputs to the IRB capital formula by adopting through-the-cycle rating methodologies effectively reduces capital volatility, but at great cost. Changes in a bank's capital requirements over time would be only weakly correlated with changes in its economic capital, and there would be no means to infer economic capital from regulatory capital. Thus, Pillar 3 disclosures would fail to help market participants monitor banks over time. Furthermore, as through-the-cycle ratings are less sensitive to market conditions than point-in-time ratings, they are less useful for active portfolio management and as inputs to ratings-based pricing models such as Jarrow, Lando and Turnbull (1997). Not suprisingly, most large banks in the US seek to rate in a point-in-time fashion (Treacy and Carey 1998).

Dampening inside IRB's "black box" by flattening the capital formula poses the opposite trade-off. So long as the flattening is modest and uniform across loan types, the information value in regulatory capital is preserved, but relatively little dampening is achieved. Heavy-handed flattening of the capital formula might better succeed in dampening procyclicality, but also would distort relative capital charges across loans (and do so at every point in the business cycle). This would pave the way for continued regulatory capital arbitrage.

We favor dampening only the outputs. So long as the dampening rule is public and applied only at the level of aggregate portfolio capital requirements, then the unsmoothed portfolio capital requirement can be inferred by market participants - no information is sacrified. We propose two different smoothing rules. The autoregressive (AR) rule smooths required capital independently for each bank using a time-series filter. Intuitively, the AR smoothing rule causes the regulatory capital requirement to adjust slowly over time to a shock today in the bank's economic capital requirement. The counter-cyclical (CC) indexing rule applies a time-varying multiplier to the IRB formula. The multiplier is large (over one) in good times and small (under one) in bad times. It is announced in each period by the national regulator, and applied to all banks under its jurisdiction. The rules appear to be comparable in how well they dampen capital volatility and in how 
well changes in the regulatory minimum would track changes in the undampened IRB capital requirement for the portfolio. Neither would impose additional operational burden on banks. However, they would differ significantly in implementational challenges. The great advantage to the autoregressive rule is that it is decentralized. Because it depends only on the bank's own time-series of IRB capital requirements, it does not disadvantage banks operating in local markets with business cycles distinct from the overall national market. Furthermore, the regulator is a passive observer of the smoothing, and is not called upon to make judgements about the state of the macroeconomy that may be hard to defend empirically or politically. The disadvantage is that it implicitly assumes that the bank's lending strategy is stationary. A weak bank would have the incentive to ramp up portfolio risk rapidly, because required capital would catch up only slowly. The counter-cyclical indexing rule is robust to changing business mix at the individual bank level, which is important in markets in which large flows of financial assets can move between regulated banks and unregulated financial firms, but the $\mathrm{CC}$ rule requires the regulator to determine the multiplier appropriate to each period. Regulators in well-developed financial markets are thus more likely to favor the CC rule and to have access to financial market indicators and other data for its calibration. ${ }^{28}$ The AR approach could be better suited to smaller bank-dominated markets.

\footnotetext{
${ }^{28}$ Useful indicators in the US might include the TRAC-X credit default swap index and Altman's high-yield default index. In markets where banks hold the overwhelming share of total corporate debt, an index could be based on a moving average of the aggregate default rate for bank commercial borrowers.
} 


\section{References}

Altman, Edward I. and Herbert A. Rijken, "How Rating Agencies Achieve Rating Stability," Journal of Banking and Finance, forthcoming.

_ Brooks Brady, Andrea Resti, and Andrea Sironi, "The Link Between Default and Recovery Rates: Implications for Credit Risk Models and Procyclicality," Journal of Business, forthcoming.

Araten, Michel, Michael Jacobs, Jr., and Peeyush Varshney, "Measuring Loss Given Default on Commercial Loans for the JP Morgan Chase Wholesale Bank: An 18 Year Internal Study," Journal of the $R M A$, forthcoming.

Asarnow, Elliot and David Edwards, "Measuring Loss on Defaulted Bank Loans: a 24-Year Study," The Journal of Commercial Lending, March 1995.

Basel Committee on Bank Supervision, "The New Basel Capital Accord,” Technical Report Second Consultative Paper, Bank for International Settlements January 2001.

_ _ "Overview of The New Basel Capital Accord," Technical Report Second Consultative Paper, Bank for International Settlements January 2001.

_ , "The New Basel Capital Accord," Technical Report Third Consultative Paper, Bank for International Settlements April 2003.

Bassett, William F. and Egon Zakrajšek, "Recent Developments in Business Lending," Federal Reserve Bulletin, December 2003.

Berger, Allen N. and Gregory F. Udell, "The Institutional Memory Hypothesis and the Procyclicality of Bank Lending Behavior," December 2003.

__ Marco A. Espinosa-Vega, W. Scott Frame, and Nathan H. Miller, "Debt Maturity, Risk, and Asymmetric Information,” December 2003.

Cantor, Richard, "Moody's Investors Service Response to the Consultative Paper Issued by the Basel Committee on Bank Supervision "A New Capital Adequacy Framework"," Journal of Banking and Finance, 2001, 25, 171-185.

and C. Mann, "Are Corporate Bond Ratings Procyclical?," Special Comment, Moody's Investor Services October 2003.

Carey, Mark and Mark Hrycay, "Parameterizing Credit Risk Models with Rating Data," Journal of Banking and Finance, 2001, 25, 197-270.

, Mitch Post, and Steven A. Sharpe, "Does Corporate Lending by Banks and Finance Companies Differ? Evidence on Specialization in Private Debt Contracting," Journal of Finance, June 1998, 53 (3), 845-878.

Catarineu-Rabell, Eva, Patricia Jackson, and Dimitrios Tsomocos, "Procyclicality and the New Basel Accord - Banks' Choice of Loan Rating System,” Working Paper 181, Bank of England March 2003.

Christensen, Jens, Ernst Hansen, and David Lando, "Confidence Sets for Continuous-time Rating Transition Probabilities," Journal of Banking and Finance, forthcoming. 
Cosandey, David and Urs Wolf, “Avoiding pro-cyclicality," Risk, October 2002.

Düllmann, Klaus and Harald Scheule, "Asset Correlation of German Corporate Obligors: Its Estimation, Its Drivers and Implications for Regulatory Capital,” March 2003.

Ervin, D. Wilson and Tom Wilde, "Pro-cyclicality in the new Basel Accord," Risk, October 2001.

Flannery, Mark J. and Kasturi P. Rangan, "Market Forces at Work in the Banking Industry: Evidence from the Capital Buildup of the 1990s," September 2002.

Frye, Jon, “A False Sense of Security,” Risk, August 2003, 16 (8), 63-67.

Furfine, Craig, "Evidence on the response of US banks to changes in capital requirements," Working Paper 88, Bank for International Settlements June 2000.

Gordy, Michael and Erik Heitfield, "Estimating Default Correlations from Short Panels of Credit Rating Performance Data," January 2002.

Gordy, Michael B., "A Comparative Anatomy of Credit Risk Models," Journal of Banking and Finance, January 2000, 24 (1-2), 119-149.

_ , "A Risk-Factor Model Foundation for Ratings-Based Bank Capital Rules," Journal of Financial Intermediation, July 2003, 12 (3), 199-232.

__ , "Granularity Adjustment in Portfolio Credit Risk Measurement," in Giorgio P. Szegö, ed., Risk Measures for the 21st Century, John Wiley \& Sons, 2004.

Gupton, Greg M., Christopher C. Finger, and Mickey Bhatia, CreditMetrics-Technical Document J.P. Morgan \& Co. April 1997.

Heitfield, Erik, "Rating System Dynamics and Bank-Reported Default Probabilities under the New Basel Capital Accord," April 2004.

Jarrow, Robert, David Lando, and Stuart Turnbull, "A Markov Model for the Term Structure of Credit Risk Spreads," Review of Financial Studies, 1997, 10, 481-523.

Jokivuolle, Esa and Samu Peura, "Regulatory Capital Volatility,” Risk, May 2001, pp. 95-98.

Jones, David, "Emerging problems with the Basel Capital Accord: Regulatory capital arbitrage and related issues," Journal of Banking and Finance, January 2000, 24 (1-2), 35-58.

Jordan, John, Joe Peek, and Eric Rosengren, "Credit Risk Modeling and the Cyclicality of Capital," October 2003.

Kalkbrenner, Michael and Ludger Overbeck, “The maturity effect on credit risk capital,” Risk, July 2002, 15 (7).

Kashyap, Anil K. and Jeremy C. Stein, "Cyclical Implications of the Basel-II Capital Standards,” 2003.

and ___ , "Cyclical Implications of the Basel-II Capital Standard," Federal Reserve Bank of Chicago Economic Perspectives, First Quarter 2004, pp. 18-31.

Löffler, Gunter, "Avoiding the Rating Bounce: Why Rating Agencies are Slow to React to New Information," Technical Report, University of Frankfurt June 2002. 
, "An Anatomy of Rating Through the Cycle," Journal of Banking and Finance, March 2004, 28 (3), $695-720$.

Merton, Robert C., "On the Pricing of Corporate Debt: The Risk Structure of Interest Rates," Journal of Finance, 1974, 29, 449-470.

Morgan, Donald P., "Rating Banks: Risk and Uncertainty in an Opaque Industry," American Economic Review, September 2002, 92 (4), 874-888.

Purhonen, Martti, “New Evidence of IRB Volatility,” Risk, March 2002.

Rösch, Daniel, “Mitigating procyclicality in Basel II: A value at risk based remedy,” 2002. 'working paper'.

Rösch, Daniel, "An Empirical Comparison of Default Risk Forecasts from Alternative Credit Rating Philosophies," October 2003.

Rowe, David, "Is 8\% for all seasons?," Risk, May 2003.

Study Group on Subordinated Notes and Debentures, "Using Subordinated Debt as an Instrument of Market Discipline,” Technical Report Staff Study 172, Federal Reserve System December 1999.

Treacy, William F. and Mark S. Carey, "Credit Risk Rating at Large U.S. Banks," Federal Reserve Bulletin, November 1998, 84 (11), 897-921.

Wong, H.Y. and N.H. Chan, "A Structural Model for Credit Migrations,” 2002. 